\title{
PARTICIPAR É PRECISO! MAS DE QUE MANEIRA?
}

\section{Julio César Donadone e Roberto Grün}

\section{Introdução}

As transformações do espaço econômico, e das formas organizacionais em específico, fornecem elementos para uma análise de aspectos essenciais das formas pelas quais o poder é conquistado e exercido na moderna sociedade brasileira. Pretendemos contribuir para a análise de alguns pontos dessa evolução recente, a partir da questão da transformação das formas de gestão empresariais e da difusão e implementação da participação dos trabalhadores na gestão, em particular. Pretendemos também sustentar que esse fenômeno só pode ser entendido se o apresentarmos como a evolução de um contencioso cultural, apesar de estar no centro da esfera econômica. O estudo da evolução do significado do termo "participação", mote que transformou decisivamente a cena empresarial a partir dos anos 80, também pode ser utilizado indutivamente para entendermos a rápida recuperação do poder nas empresas pelos patrões e gerentes, após o período de contestação que se abriu com as greves operárias de 1978. Nosso ponto central é que esse fenômeno só pode ser entendido numa configuração em que recursos econômicos e culturais sejam acionados cumulativamente. Na análise dos embates trabalhistas, acostumamo-nos a prestar atenção nos primeiros e perdemos a dimensão da essencialidade dos últimos. Talvez esse olhar tradicional seja capaz de dar conta das conjunturas momentâneas. Certamente, é incapaz de contemplar as profundas transformações multifacetadas por que a sociedade brasileira tem passado recentemente. ${ }^{1}$

Numa primeira aproximação, a difusão e a transformação da idéia de participação podem ser descritas a partir da noção de campo (Bourdieu, 1989). De início, observamos a tentativa de setores do movimento operário e sindical de utilizar essa bandeira no quadro de algumas variantes das estratégias de emancipação do proletariado. Grupos em geral situados à esquerda do es- 
pectro das possibilidades de representação dos grupos subalternos propagandeavam essa bandeira no intuito de fomentar o renascimento da contestação adormecida durante o período militar. Esse "eixo de lutas" tinha também a intenção de criar um ponto de diferenciação dos grupos contestadores em relação à esquerda tradicional e às burocracias sindicais. A estratégia configurava-se na tentativa de criar as comissões de fábrica. A princípio uma característica exclusiva desses grupos, a idéia das comissões ganhou maior notoriedade quando foi adotada pelos sindicalistas de Osasco (São Paulo) nas greves de 1968 e, já no ocaso do regime militar (1978/1979), quando utilizada pelos metalúrgicos do $\mathrm{ABC}$ a partir do momento em que seus sindicatos tornaram-se objeto de intervenção governamental. Paralelamente, e com muito menor expressão, apareciam experiências isoladas, suscitadas em empresas que começavam a importar os modismos empresariais japoneses e suecos na segunda metade dos anos 70. Em princípio, os dois grupos de eventos eram totalmente independentes, não faziam parte do mesmo campo gravitacional e a ninguém ocorria relacioná-los.

Do lado empresarial, a década de 80 foi marcada pelo incremento no ritmo de introdução de mudanças tecnológicas e organizacionais nas empresas brasileiras. Tais mudanças foram manifestamente motivadas pela necessidade de fazer com que as empresas reagissem à recessão econômica interna e buscassem mercados exteriores. Conceitos como qualidade e flexibilidade surgiram no elenco de inovações adotadas, visando reestruturar a produção industrial e, assim, melhorar os índices de competitividade.

Dentre as mudanças de natureza organizacional propostas naquele momento, evidenciavase, de maneira mais freqüente, a procura de uma nova relação entre as empresas e seus funcionários, o que proporcionou o desenvolvimento de formas de negociação e integração entre empregado e empregador até então inéditas na história brasileira. Entre essas formas surgem os chamados "sistemas participativos", que se difundiram nas organizações brasileiras nos anos que se seguiram, resultando em uma diversidade de arranjos organizacionais e entendimentos associados ao tema "participação".

No decorrer do período, o conceito de "participação" tem seu significado alterado, adaptando-se notavelmente às mudanças de contexto ocorridas na década. Contrariando o entendimento mais comum, sustentamos que, longe de ser um problema de falta de precisão do conceito de "participação", esta plasticidade é justamente a condição para sua difusão e introdução de maneira concreta no ambiente organizacional brasileiro.

Para dar conta do processo, utilizaremos como material primário de análise o rastreamento sistemático das apreciações sobre o tema, veiculadas na imprensa de negócios brasileira, em especial a revista Exame, no período de 1967 a 1990. Esse procedimento visa observar as mudanças de sentido que o termo vai adquirindo no decorrer do tempo. Como contraponto à imprensa de negócios com seu caráter de porta-voz do pensamento gerencial e empresarial, serão utilizados os dados que constam nos arquivos de publicações sindicais das décadas de 70 e 80 do Departamento Intersindical de Estudos Estatísticos e Socioeconômicos (Dieese), buscando, assim, sistematizar a visão sindical sobre o tema. O material de análise será complementado por informações extraídas de entrevistas com participantes do processo de difusão, por exemplo, jornalistas, membros de associações profissionais, empresas de consultoria, e pela consulta da literatura sobre o assunto.

\section{A difusão de idéias versus a difusão de práticas}

Para que se compreenda como as idéias sobre "participação" foram incorporadas e transformadas em "prática" nas organizações brasileiras, considerou-se a análise dos diversos significados atribuídos ao tema no transcorrer da década de 80 .

O conceito de participação foi se modificando em virtude da existência de uma disputa entre os diversos setores - empresarial, sindical e gerencial - pela definição válida na sociedade, acerca do conteúdo das novidades organizacionais associadas ao tema. Para que se entenda essa plastici- 
dade, utiliza-se como conceito central a idéia de "polissemia", segundo a extensão sociológica do conceito originário da lingüística, proposta por Bourdieu (1989). Nesta acepção, entende-se por polissemia o sentido parcialmente compartilhado para um determinado conceito, sob o qual os entendimentos implícitos em torno de sua definição se fixam. Este compartilhamento apenas parcial garante um mínimo de acordo e evita uma crise na relação entre os contendores, para depois evoluir como conflitos simbólicos, em que cada parte tenta registrar como correta a sua versão específica. Em outras palavras, no nosso universo empírico, o entendimento parcial em torno do tema "participação" possibilitou a negociação entre os empregados e as empresas durante os movimentos grevistas de 1978, garantindo benefícios mútuos, com o reconhecimento do sindicato como interlocutor dos trabalhadores pelas empresas e a utilização desse canal de comunicação como forma de resolver os conflitos trabalhistas.

Ainda de acordo com a sugestão de Bourdieu, podemos notar que no começo da década de 80 a ação simultânea dos diversos agentes acaba formando um "campo" em torno do tema, onde indivíduos originários dos mais diversos sub-espaços sociais e portadores de elencos de qualidades também das mais diversas acabavam, a despeito da desconfiança e da incompreensão mútuas, colaborando para sua difusão e consolidação nas organizações brasileiras. Nesse processo aparentemente natural, a partir de propostas e retificações consecutivas que iam e voltavam depois de testadas e/ou se incorporavam à produção de sentido, acabou-se construindo o entendimento comum mínimo sobre o tema "participação". Diversos agentes apropriavam-se dele em suas respectivas arenas mais ou menos isoladas (sindicais, gerenciais, patronais, acadêmicas, governamentais), e a adesão ao debate lhes ajudava a alcançar objetivos específicos. Ao mesmo tempo, esse concerto sem maestro acabava por indicar o sentido do futuro das relações trabalhistas brasileiras.

Depois de algum tempo, esse acordo explícito inicial, que colocou o tema da "participação" na agenda de discussões legítimas no mundo empresarial e na sociedade como um todo, evoluiu para uma luta simbólica, em que os diversos grupos sociais tentaram legitimar sua versão de "participação", desqualificando as demais formas. Cada grupo de atores envolvido com o tema buscava uma compreensão própria sobre as práticas participativas veiculadas às idéias japonesas de gestão e a outras de mudanças organizacionais, utilizando-a na tentativa de alavancar e fortalecer sua posição frente aos concorrentes do campo.

A luta pela definição social do significado da "participação", além de fornecer os diversos entendimentos sobre o tema, surgiu como um dos pontos principais do processo de difusão das tecnologias organizacionais associadas às idéias de gestão oriunda da chamada administração industrial japonesa e também da "reengenharia" no decorrer da década de 90. Estamos diante da versão brasileira de um processo mais geral do processo de difusão de novas tecnologias, que Cole (1989) inspiradamente definiu como o ato de "reinventar a roda". A partir dessa trama, as novidades organizacionais associadas à "participação" difundiram-se no transcorrer dos anos 80. Porém, elas somente entraram no cotidiano das empresas após um processo de apropriação e recontextualização, quando seu "espírito" foi progressivamente assimilado a práticas já conhecidas no nosso ambiente, fornecendo-lhes um sentido compreensível no sistema social das organizações brasileiras. Por exemplo, pode-se citar a utilização de metáforas nos meios gerenciais brasileiros no final dos anos 80, associando o tema "participação" a aspectos recorrentes do futebol. Uma das mais freqüentes era a idéia de "quem ganha o jogo é o time". Com isso, ressaltava-se que, assim como no futebol, também nas empresas o sucesso dependia do grupo, pois, segundo a crônica futebolística, não havia mais espaço para um "craque" que sozinho resolveria o jogo, atuando somente no ataque. Havia a necessidade tanto de "fazer gols", quanto de "ajudar na defesa".

\section{A "participação dos trabalhadores" antes da década de 80: "O Estranho no Ninho"}

Para compatibilizar as séries nas duas fontes principais de consulta, construímos uma periodi- 
zação que tem como primeira fase o período de 1967 a 1977. A escolha do ano de 1967 como ponto de partida deve-se, por um lado, ao fato de ter sido neste ano o lançamento do encarte "Negócios em Exame" nas revistas técnicas da Editora Abril, que posteriormente, em 1971, se tornaria a revista Exame, uma das fontes primárias deste trabalho. De outro lado, essa escolha também insere na análise as greves de Contagem e Osasco ocorridas em 1968, que forneceram importantes elementos para a caracterização da visão sindical sobre o tema "participação" no período anterior aos anos 80. Paralelamente, o termo "executivo", querendo dizer "gerente profissional", começa a aparecer nas publicações, denotando a consagração da cidadania simbólica desse novo personagem.

Ao analisar o período de 1967 a 1977, a primeira constatação a que se chega é que o tema participação era pouco evidenciado. Diversos fatores contribuíram para que ele não fosse divulgado. Na esfera política, o autoritarismo e as formas de repressão utilizadas pelo regime militar inibiam ou tornavam desnecessária a constatação de problemas de relações trabalhistas. Na imprensa de

\section{Quadro 1 \\ A Estranheza}

No período de 1967 a 1978, as citações na imprensa de negócios sobre empresas que implementavam alguma forma diferente de relacionamento com seus funcionários eram em número reduzido e apresentadas como "algo estranho" à gestão empresarial da época. Ao se pesquisar a revista Exame no decorrer desse período, encontram-se apenas duas referências de empresas que buscavam maior interação com os funcionários: a Incepa e a Lafer.

Em entrevista à revista Exame, a empresa Incepa (Indústria de Cerâmica do Paraná) tinha de responder à pergunta: Que tipo de capitalismo é esse? Tal questão era respaldada, segundo a revista, no fato de que na fábrica não havia fiscais e os produtos fabricados eram considerados de alta qualidade, contando para isso não apenas com um maquinário moderno, mas com o esforço dos operários na avaliação da produção. Nas palavras de um dos seus diretores: "os funcionários vendem uma espécie de dedicação", associando a esse maior envolvimento com a produção as vantagens de que dispunham os empregados da empresa.

Com a frase "O quadro é, no mínimo, insólito", a revista Exame descrevia a experiência da Lafer. O que despertava a atenção e merecia o título de "insólito" era a experiência de "participação" desenvolvida na empresa, que envolvia os empregados na discussão de problemas da firma visando a melhoria da produtividade. Isso era feito da seguinte forma: reunia-se um grupo de empregados, principalmente marceneiros e estampadores encarregados de seção, sob a orientação do gerente administrativo da empresa, e transmitiam-se conceitos de custos, produtividade, margem de contribuição, estoques, consumo de matérias-primas, uso de mão-deobra e horas extras.

Segundo o gerente administrativo, Thomas M. Lanz, o objetivo era fazer com que o empregado fosse parte integrante da empresa; como é possível observar em suas palavras: "Somente conhecendo toda a empresa o funcionário pode entender, por exemplo, a necessidade de acelerar a produção para dar conta de um programa de exportações cujo prazo foi reduzido". O objetivo final, conforme a empresa, era que as discussões pudessem ser feitas dentro de cada setor com os responsáveis, reduzindo, com isso, o desperdício de matéria-prima e propiciando um incremento na produtividade.

Cabe ressaltar que, nos dois exemplos, as reportagens apresentavam as experiências das empresas como "curiosas relações com os empregados" e ocupavam pequeno destaque na revista. A ampliação da intervenção dos trabalhadores e a utilização de sugestões dos empregados, mesmo em esferas específicas da produção, apareciam como algo incomum e lembravam as idéias de autonomia operária ("não havia fiscais na fabrica.") ou interferência na gestão das empresas pelos trabalhadores (que capitalismo é esse ?) 
negócios, o tema era pouco citado e os esporádicos exemplos resumiam-se a notícias sobre empresas que adotavam "estranhas formas de gestão”, apresentando o assunto para os leitores/gerentes mais como uma curiosidade do que como um exemplo passível de ser empregado no gerenciamento das empresas.

Do lado sindical, o quadro não era diferente. Ao pesquisar os artigos publicados nos boletins do Dieese, durante o período de 1967 a 1978, não foi encontrada qualquer referência ao tema, e mesmo nas greves de 1968 em Contagem e Osasco, a participação via "comissões de fábrica" aparecia como uma ameaça às posições dos sindicatos, no entender da maioria dos dirigentes sindicais da época. Como exemplo, é possível considerar o fato de que a Volkswagem, em 1971, a Johnson \& Johnson, em 1972, e a Empresa Brasileira de Aeronáutica (Embraer), em 1974, introduziram Círculos de Controle de Qualidade (CCQs) e não foram notícia na revista Exame, nem tampouco nas publicações sindicais do período. Tais posturas diferiam daquelas adotadas na década de 80, quando a participação, associada aos CCQs, recebia expressiva divulgação na imprensa de negócios e críticas constantes nos jornais e boletins sindicais.

\section{A difusão de idéias associadas à "partici- pação dos trabalhadores" na década de 80}

A difusão de idéias sobre "participação" dos trabalhadores foi influenciada por acontecimentos políticos e sociais no decorrer da década de 80. O fim do regime militar, as greves de 1978, a recessão dos anos de 1980 a 1983 e a atuação dos diversos setores sociais envolvidos induziram a um número crescente de experiências associadas ao tema.

Diferentemente do período de 1967 a 1978, as idéias de "participação" começavam a ganhar evidência no final dos anos 70. Tal fato deve-se, principalmente, ao ressurgimento dos movimentos trabalhistas e sindicais, após as greves de 1978. Com a perda de espaço do governo, que anteriormente mediava a relação entre empresários e trabalhadores, coube a estes vivenciarem a experiên- cia da negociação direta, na tentativa de resolver os embates trabalhistas. Esse fato impulsionou a discussão das formas de intervenção dos operários em aspectos da vida das empresas, proporcionando os primeiros significados associados à participação da década de 80. Os primeiros exemplos da introdução de "Representantes dos Trabalhadores" e "Delegados Sindicais", a criação de "comissões de fábrica" e a discussão sobre a intervenção dos trabalhadores em assuntos referentes ao mundo fabril colocavam em evidência o tema da "participação dos trabalhadores nas empresas", fornecendo-lhe um entendimento básico nessa primeira fase do período.

$\mathrm{O}$ assunto era destaque nas publicações sindicais, aparecendo como um dos fatores que diferenciavam o sindicalismo que surgiu após as greves de 1978 das formas anteriores, então chamadas de "pelegas". Assim, a "participação" estava associada a formas de negociação direta com o patronato e à possibilidade de ampliação do elenco das pautas de reivindicação, passando a abranger não somente aspectos salariais, mas também questões relacionadas ao cotidiano do chão da fábrica.

$\mathrm{Na}$ estratégia geral do movimento sindical da época, a participação surgia como uma alternativa de atuação em face da ação repressora do regime militar. Negociando com as empresas a introdução de representantes dos trabalhadores, os dirigentes sindicais vislumbravam uma forma de garantir a atuação do movimento sindical ante a possibilidade sempre crescente de cassação de líderes e de intervenção nos sindicatos pelo governo militar.

Mas não era apenas nos meios sindicais que o tema "participação" recebia destaque. Ele começava a ser pauta também nas publicações empresariais e gerenciais. As notícias apresentavam exemplos de empresas que estabeleciam "novas formas" de negociação com os empregados, na tentativa de solucionar os embates trabalhistas por elas enfrentadas com o recrudescimento do movimento sindical no "pós-1978" e a mitigação na atuação do governo como mediador entre empregados e empregadores que era, até então, exercida amplamente pelo regime militar. Surgiam os primeiros exemplos de empresários e gerentes discutindo a respeito da "participação", mais espe- 
cificamente sobre a criação de representantes dos trabalhadores nas empresas, para evitar que problemas que pudessem ser resolvidos no interior da empresa fossem direcionados para possíveis movimentos grevistas. ${ }^{2}$

O início da divulgação e da discussão de significados atribuídos ao tema "participação", que resultou na criação de Representantes de Empresas e Comissões de Fábrica, e na introdução do Delegado Sindical, é de grande valia para a proposta de explicação do caráter polissêmico do conceito. No período de 1978 a 1982, a "participação", considerada um canal de comunicação, começava a ser divulgada na imprensa de negócios e aceita tanto nas empresas quanto nos meios sindicais. Cabe lembrar que as comissões de fábrica eram também uma outra forma de apresentar os representantes dos trabalhadores nas empresas, diferindo no grau de controle sindical.

Do quadro depreende-se o início de reconhecimento patronal para a questão da participação e é difícil deixar de notar que a impugnação

\section{Quadro 2 \\ A Imprensa de Negócios e o Início do Reconhecimento da Participação enquanto Reivindicação Sindical}

Na imprensa de negócios, as questões trabalhistas ganharam espaço com as greves de 1978 e, principalmente, com os debates sobre a livre negociação entre empresas e trabalhadores. Como exemplo, a revista Exame afirmava que: "As negociações diretas ultrapassaram dissídios. Agora parece inevitável que a legislação trabalhista, anacrônica e revogada na prática, tenha que se curvar aos fatos, adaptando-se à realidade”. Essa postura da revista era importante, pois, por um lado, ao referendar os procedimentos da livre negociação, a publicação ajudava a legitimar os sindicatos como "um dos negociadores", abrindo a possibilidade de inserção da opinião de trabalhadores em outros assuntos referentes ao funcionamento das empresas. Por outro lado, a revista cumpria um papel "generalizador" das relações trabalhistas consideradas mais avançadas no Brasil da época, divulgando e impondo aos seus gerentes/leitores novas formas legítimas de pensar as relações trabalhistas.

A publicação passava a elogiar e evidenciar as soluções "inovadoras" para o relacionamento das empresas com seus funcionários, diferentemente do período de 1967 a 1978, quando tais iniciativas recebiam rótulos de "estranhas experiências". A "participação" aparecia como um canal de comunicação e influência sobre os empregados e os exemplos estavam relacionados à introdução do Delegado Sindical e à criação de Representantes dos Trabalhadores nas empresas, como mostrado a seguir.
Empresários a favor:

"Um representante dos empregados ajudaria a corrigir muitos erros, pois, em geral, ele não está contra a empresa, mas disposto a ajudar". Antônio Carlos Simeira Jacob, diretor superintendente da Etti.

"Inicialmente, o delegado sindical irá causar alguns problemas para a empresa. Mas, com o tempo, tudo irá se normalizar". Sérgio Mindlin, diretor de planejamento da Metal Leve.

"O delegado é o canal de comunicação, reivindicação e pressão do operário em relação ao patrão". Manuel Antônio Lopes, diretor superintendente da Ultratec e vice-presidente executivo da Associação Brasileira de Engenharia Industrial.

Empresários contra:

"O país não está preparado. Primeiro é preciso sair do Mobral". Nadir Figueiredo, presidente da Nadir Figueiredo Ind. Com. Ltda.

"Em face das condições atuais do país, o delegado sindical poderia trazer prejuízos aos empregados, porque haveria a mistura de reivindicações de natureza política com as de interesse direto da produção". Paulo Cunha, vice-presidente do grupo Ultra e presidente da Associação Brasileira de Indústria Química e de Produtos Derivados, Abiquim. 
mais forte à nova prática surge justamente de Nadir Figueiredo, um dos barões da antiga Fiesp, totalmente alinhada ao cuore do regime militar. Os empresários favoráveis eram justamente aqueles que se insurgiam contra a chamada oligarquia da representação patronal, fazendo-nos crer que "participação" era também um dos pontos em torno dos quais se urdia as estratégias de diferenciação do "novo patronato". E na esfera das relações trabalhistas, o período entre o fim dos anos 70 e o início da década de 80 marcou os primórdios desse entendimento parcial em torno do conteúdo associado ao tema "participação", possibilitando a negociação entre os empregados e as empresas durante os movimentos grevistas de 1978 e garantindo benefícios mútuos, como o reconhecimento do sindicato como interlocutor dos trabalhadores pelas empresas. Esse processo propiciou a continuidade da atuação do sindicato ante as condições políticas da época e consolidou a utilização pelas empresas desse canal de comunicação como forma de resolver os conflitos trabalhistas. No universo empresarial, além de ser um ponto nas estratégias de diferenciação interna ao campo, a canalização dos conflitos exorcizava os fantasmas da eclosão de "greves selvagens", que tanto assustaram aqueles que acompanharam a cena européia do final dos anos 60 e início da década de 70. Além disso, internamente ao campo gerencial, a questão trabalhista fazia emergir ou simplesmente aumentar a relevância dos agentes que tinham na "gestão dos recursos humanos" a sua razão de ser dentro da empresa.

No cotidiano do embate, partindo do núcleo comum da importância do tema, realçada de maneira diferente, mas convergente por todos os seus participantes, cada grupo tentava forçar o significado do tema "participação", vendo nesse processo uma forma de alcançar os objetivos específicos sobre o que eles imaginavam ser o futuro desejado das relações trabalhistas e, evidentemente, o seu próprio futuro nos campos onde as fichas estavam sendo jogadas. Estavam lançadas as idéias de envolvimento operário com as empresas, as quais posteriormente, no transcorrer da década de 80, receberiam novos significados.

\section{Participação e produtividade: o período de 1982 a 1987}

Na primeira metade dos anos 80, outro elemento incrementou a difusão das idéias de participação. A forte recessão interna de 1980 a 1983 fez com que as empresas buscassem a melhoria dos índices de produtividade para sobreviver nos mercados internos em retração e possibilitar a introdução dos produtos brasileiros nos mercados externos, considerados mais competitivos. Esses fatos, entre outros, ocasionaram um aumento no ritmo de introdução das mudanças organizacionais nas empresas brasileiras.

Consonante com as idéias então em voga nos espaços empresariais dos países desenvolvidos, destacava-se, entre as mudanças, a implementação de ferramentas gerenciais inspiradas nas idéias de gestão empresarial japonesa, tal como eram retratadas em publicações da imprensa de negócios norte-americana. Tais ferramentas, respaldadas pela divulgação do sucesso das indústrias japonesas, em especial no que diz respeito à conquista de consideráveis parcelas do mercado norte-americano de automóveis, apareciam como uma referência para as empresas brasileiras que buscavam superar os problemas ocasionados pela recessão.

A introdução de formas de gestão japonesa por meio de programas de qualidade causou um significativo incremento na difusão de idéias associadas à "participação". Em especial, a divulgação e a implantação de ferramentas gerenciais que propunham a utilização de intervenções dos trabalhadores nos acontecimentos do chão de fábrica como uma forma de aumento da produtividade e melhoria da qualidade dos produtos.

Na metade da década de 80, entre as várias mudanças organizacionais associadas a "idéias japonesas" de gestão da produção, surgiam com destaque os Círculos de Controle da Qualidade (CCQs). Com os CCQs, o tema "participação" ganhava generalidade e relevância nas discussões empresariais e gerenciais. Sua divulgação tornavase freqüente na imprensa de negócios, principalmente, por meio de exemplos de empresas que estavam implementando alguma forma de envolvimento dos operários com a produção. 


\section{Quadro 3}

\section{Participação e Produtividade}

As referências na imprensa de negócios

Na primeira metade da década de 80, os "programas de sugestão" aparecem como uma das primeiras formas de envolvimento e integração dos empregados. As sugestões e opiniões dos empregados, visando a melhoria nos processos de produção, foram um dos instrumentos gerenciais utilizados pelas empresas para conseguir superar as dificuldades da crise econômica. Conforme afirmava Luís Washington Fonseca, superintendente industrial da Divisão de elevadores das indústrias Villares: "Mostrar aos empregados que estamos num mesmo barco, temos igual interesse em que a empresa progrida, tornou-se vital para quem quer sobreviver no mercado".

Seguindo essa mesma direção, diversas empresas procuraram alterar seus planos quanto à produtividade. De um lado, buscaram intensificar o uso de seus equipamentos e dar ênfase ao treinamento da mão-de-obra; em outro plano, enfocaram a questão dos programas motivacionais, que visavam criar o envolvimento e a integração de empregados com a empresa para que esses "vestissem a camisa", como afirmava o superintendente da Villares.
Um exemplo indicativo dos "programas de sugestões" da época era o lema "juntos para o futuro", promovido pela Volkswagen de São Bernardo, nos primeiros meses de 1982. A indústria automobilística era um dos setores mais pressionados pela necessidade de modernização, devido à redução de $20 \%$ na produção em relação ao ano de 1980 e às primeiras tentativas de introduzir seus produtos em mercados internacionais competitivos. O programa da Volkswagem consistia na coleta de sugestões em relação à segurança, ao processo de trabalho e à qualidade, entre outros assuntos, para, através do estímulo de prêmios, reduzir custos e obter melhorias no funcionamento da empresa.

$\mathrm{Na}$ imprensa de negócios, os "Programas de Sugestão" ganhavam destaque e os artigos descreviam experiências de empresas que utilizavam as sugestões dos empregados a respeito de aspectos da produção para o aumento da produtividade. No transcorrer do texto, serão apresentados exemplos de empresas que na época serviam como pontos de referência quanto à aplicação e divulgação da "participação" para alcançar seus objetivos de produtividade e competitividade.
Como exemplo do crescimento das publicações sobre o tema "participação" que utilizava o modelo japonês como referência, temos o gráfico a seguir.

\section{Os CCQs na Revista Exame}

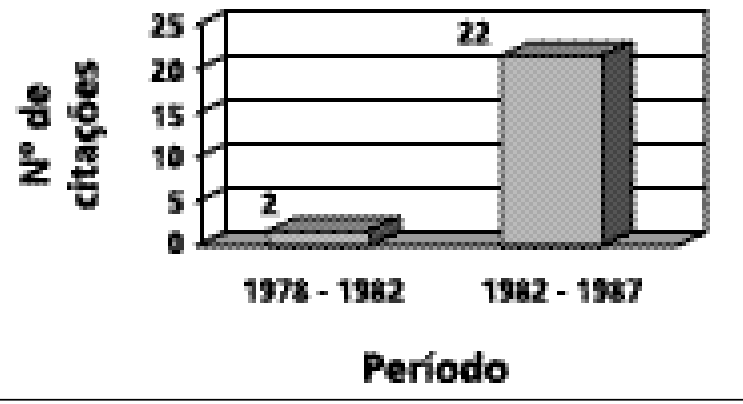

Mas não era apenas na imprensa de negócios que a "participação" ganhava espaço. Nas publicações sindicais isso também ocorria. No período entre 1982 e 1987, apareceram diversos artigos que criticavam o envolvimento do operário com a empresa através dos CCQs. Tais publicações, ainda que de forma inversa à imprensa de negócios, ajudavam na difusão das idéias de "participação", principalmente por meio de discussões e publicações que buscavam contrastar a visão sindical de "participação", preponderantemente associada às Comissões de Fábrica, do ponto de vista gerencial representado, principalmente, pelos CCQs.

Naquele momento, os antagonismos escamoteados no acordo inicial em torno de tema "participação" começavam a aparecer em novas conten- 
das. O contencioso tornava-se nítido através do embate entre as Comissões de Fábrica e os Círculos de Controle de Qualidade. As comissões associavam ao tema um conceito que o apresentava como um instrumento de atuação operária no interior das empresas, possibilitando a intervenção sindical em assuntos relacionados à gestão e ao funcionamento das mesmas. Já com os CCQs, o significado atribuído à "participação" passava a associá-la a uma ferramenta gerencial que utilizava os canais de comunicação com a finalidade de redução de custos e integração dos funcionários e, em muitos casos, também na tentativa de diminuir a influência dos sindicatos nos ambientes fabris.

Entretanto, cabe ressaltar, que a variação dos significados (polissemia) atribuídos à "participação" de acordo com os setores envolvidos consolida o campo em torno do tema. O conceito foi gradualmente se institucionalizando nos meios empresariais, gerenciais e sindicais brasileiros no decorrer da década de 80, contando para isso com: i) as empresas, que passaram a visualizá-la como uma das possíveis ferramentas gerenciais de aumento da produtividade; ii) a imprensa de negócios, que encontrava um ótimo filão jornalístico na divulgação de "novidades tecnológicas e organizacionais", estruturando um setor especializado. Isso colaborava em muito para a divulgação de exemplos de implementação e discussões a respeito da necessidade de os gerentes implementarem a participação dos trabalhadores; iii) o meio sindical, que contribuía por meio de reivindicações e da introdução de formas de intervenção operária, representadas principalmente pelas Comissões de Fábrica, e também pelo crescente número de publicações que discutiam os CCQs. Além desses fatores, não se pode deixar de mencionar a atuação de firmas de consultoria que implementavam "programas de qualidade", com a presença de CCQs em muito deles.

Dessa maneira, fica claro que o período diferenciou-se dos anos anteriores, quando eram esporádicos os exemplos de empresas que buscavam alguma forma de envolvimento dos funcionários, e o assunto praticamente não figurava nas publicações da imprensa de negócios ou de organizações sindicais.

\section{A “administração participativa"}

No final da década de 80, novos elementos viriam modificar o conteúdo associado às idéias sobre a participação dos trabalhadores e incrementar seu processo de difusão. Nesse período começavam a ser divulgadas e implementadas as idéias de reengenharia, enfatizando a necessidade de uma maior flexibilidade de atuação das empresas, com o objetivo de um acompanhamento mais adequado das oscilações do mercado interno e de um aumento da competitividade nas exportações. As mudanças organizacionais associadas à reengenharia enfocavam a simplificação e a redefinição das estruturas administrativas das empresas, principalmente por redução de níveis hierárquicos e reformulação dos atributos gerenciais; e a implantação da "participação" dos operários para agilizar a solução e a comunicação de problemas relacionados com a produção.

No período, o tema "participação" ganhou destaque e espaço nas publicações da imprensa brasileira de negócios. Na revista Exame, o assunto que se tornara pauta no transcorrer dos anos 80, recebeu uma atenção ainda maior, ocupando a capa, pela primeira vez na história da revista, na edição de março de 1990, com o título: "Quem ganha o jogo é o time. O começo do fim da era do one man show, os ideais da chamada 'administração participativa', na qual a voz do empregado é moeda forte, invadem os escritórios de todo mundo".

O processo de difusão das idéias de downsizing, a reorganização dos processos decisórios e a redução dos níveis hierárquicos trouxeram modificações no significado atribuído ao conceito de participação dos trabalhadores na imprensa de negócios e nas empresas. No final da década, com a divulgação das idéias de reengenharia, a "participação" passava ser associada não somente ao aumento da produtividade no chão de fábrica, como foram os CCQs, mas também à redistribuição dos processos de decisão na empresa. Na metade da década de 80, auge da divulgação das idéias sobre a administração industrial japonesa, a "participação" estava associada ao Círculo de Controle de Qualidade, designando uma função de 
acompanhamento do transcorrer do fluxo de produção com o objetivo de redução de custos; na época da reengenharia, o tema vinha inserido na Administração Participativa, ou seja, o envolvimento operário visando a flexibilidade das ações e a troca de informações na empresa, e tornando desnecessária a supervisão direta e os diversos níveis de gerenciamento, que passaram a ser vistos como fontes de enrijecimento e de "burocratização" das decisões da empresa.

Apesar de os dados disponíveis sobre a utilização de CCQs nas empresas serem imprecisos, pode-se observar que essa caracterização de "participação" começou a decair na imprensa de negócios e nas empresas a partir de 1987, como se demonstra a seguir.

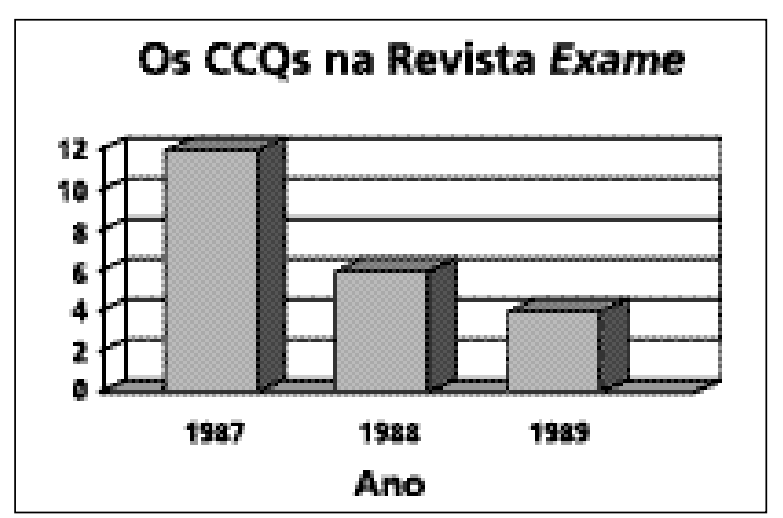

Fonte: Yokoyama, 1996.

Dados da Fundação Chistiano Ottoni (atual FDG), uma das principais entidades de divulgação das idéias sobre as ferramentas gerenciais da qualidade, confirmavam a tendência apontada anteriormente. Uma pesquisa realizada em 164 empresas em todo o país, no ano de 1991, indicou que $30 \%$ das empresas que introduziram os Círculos de Controle de Qualidade desistiram da experiência. Segundo o consultor Claudius D'Artaghan, um dos pioneiros na implantação dos CCQs no Brasil, "os CCQs viraram um nome meio maldito, porque não funcionou em algumas empresas". Sua estimativa era que em 1988 o número de empresas que usavam o CCQ tinha sido reduzido de 2000 para 600 (revista Exame, fevereiro de 1988).

Ao se analisar a mensagem passada aos leitores/gerentes pelos exemplos da revista, depara- se com dois componentes básicos: i) quanto à "participação", é possível observar que estava associada a uma forma de agilizar e descentralizar as decisões da empresa, com o objetivo de tornar o grupo de trabalhadores o mais auto-suficiente possível para resolver problemas cotidianos da produção, visando o aumento de flexibilidade $\mathrm{e}$ produtividade e tornando desnecessária a supervisão direta; ii) quanto à função gerencial, pode-se dizer que os exemplos reportavam à necessidade de mudanças nas atitudes dos gerentes para uma maneira de administrar a empresa que levasse em conta as experiências e a possibilidade de intervenção rápida dos empregados nos acontecimentos diários, dando mais flexibilidade e agilidade nas decisões.

Como condição para sobreviver aos cortes nos cargos gerenciais, os gerentes deveriam "delegar e orientar" as tarefas, em vez de somente fiscalizá-las. Isso ficava claro nas reportagens em que se enfatizava a redução dos níveis hierárquicos. Esses níveis passaram a ser vistos como fontes de morosidade que impediam a flexibilidade da empresa. Tal direcionamento era expresso nas palavras do então presidente do grupo Rhodia, empresa referência das mudanças organizacionais do período, Edson Vaz Musa: "eu mesmo tenho grande dificuldade de delegar poderes aos outros, mas estou convencido de que esse é o caminho"; "ganharemos em dinamismo e, a médio prazo, isso fará aumentar a produtividade e a lucratividade da empresa" (revista Exame, outubro de 1990).

Além do processo mimético ocasionado pela divulgação dos exemplos de empresas que obtinham resultados "positivos" com a introdução da participação dos funcionários, há também a presença de uma forte mensagem normativa. Nas publicações da imprensa de negócios, o gerente "moderno", que tinha maiores possibilidades de sobreviver aos cortes da empresa, deveria facilitar o envolvimento dos trabalhadores nas decisões sobre os problemas cotidianos das empresas. Como exemplo desse "novo gerente", em evidência nas reportagens, há uma matéria de junho de 1990, como o título: "Os executivos dos anos noventa" - uma discussão a respeito das características do gerente dos anos 90, indicando o fortaleci- 
mento dos "bons negociadores", gerentes que proporcionavam um clima de maior envolvimento e participação dos funcionários nas decisões sobre as tarefas a serem executadas.

\section{A produção do guru gerencial brasileiro e a difusão da "administração participativa"}

No final dos anos 80, as notícias a respeito de mudanças na gestão das empresas traziam freqüentemente referências ao empresário Ricardo Semler, presidente da Semco. A sua presença era comum nas reportagens das principais revistas, figurava em diversas matérias da Exame, foi personagem das páginas amarelas da Veja, era íntimo dos leitores dos jornais Folha de S. Paulo, O Estado de S. Paulo, O Globo, Jornal do Brasil e participava dos mais requisitados programas de debates na televisão. Nenhum outro empresário, nem mesmo donos de empresas trinta ou quarenta vezes maiores que a Semco, tinha uma exposição positiva na mídia equivalente à de Semler.

Ele se converteu em "celebridade nacional", aos 28 anos, com o lançamento do livro Virando a própria mesa que, no final de 1990, alcançava a vigésima sexta edição, com 180.000 exemplares vendidos, tornando-se um best seller nacional. No livro, Semler contava como havia conseguido tornar a pequena empresa à beira da insolvência, que recebera do pai Antônio Semler em 1982, em uma empresa de porte médio alguns anos depois. Para tanto, ele indicava a resolução dos problemas financeiros no envolvimento e na participação dos funcionários por meio de mudanças na estrutura gerencial da empresa.

O livro apresentava características que o aproximavam das publicações de "sucesso" na imprensa de negócios da época, como a obra de A. Morita sobre a Sony, Made in Japan. Através das experiências empresariais e gerenciais desenvolvidas na Semco, Semler apresentava a forma de atuação dos gerentes como um "remédio" indicado para empresas que estavam "doentes" na sua estrutura organizacional. Já na abertura do livro era apresentada uma bula com explicações sobre o modo de usar, indicações (hipertensão administral e hipertrofia organizacional), e posologia (adultos em cargos de direção).

A partir das caracterizações propostas no livro de Huczynski (1993) - uma discussão sobre a formação e a atuação dos "gurus gerenciais" na década de 80 - é possível fazer um paralelo entre o livro de Semler e as obras desses "gurus" identificados com os assim chamados "gerentes-heróis”. É o caso do livro de Lee Iacocca (1996) An autobiography, em que os segredos para se obter o "sucesso gerencial" eram revelados através do relato de sua experiência em remodelar as empresas automobilísticas Ford e Chrysler, superando problemas econômicos. Assim, deve-se ter presente o caráter inédito da obra de Semler no panorama editorial brasileiro. Seu livro foi o único do gênero escrito por um brasileiro que, dessa forma, alcançou o status de "guru gerencial", de que já gozavam A. Morita e Lee Iacocca, entre outros do cenário mundial.

As características da obra de Semler representavam um importante fator para sua divulgação na imprensa de negócios. No transcorrer da década de 80, a imprensa brasileira de negócios utilizou-se da divulgação das notícias a respeito das mudanças nas empresas como um importante elemento para sua consolidação. ${ }^{4}$ Dessa maneira, no final da década, o setor de negócios brasileiro vislumbrava, na divulgação de idéias gerenciais, um importante filão de mercado, da mesma forma que a imprensa de negócios norte-americana fizera no início da década. Assim, o livro e as idéias de Semler surgiam como uma importante fonte de matérias para uma imprensa ávida de notícias e que, num procedimento considerado inevitável pelos manuais e pela cultura profissional do jornalismo, necessitava "personalizar"s (na figura do "empresário-guru") o processo de mudanças, procurando com isso contextualizar para o mundo gerencial e empresarial brasileiro as alterações organizacionais associadas às novidades empresariais de então.

No final dessa década, a mensagem de Ricardo Semler ecoava nos meios gerenciais brasileiros. Para os gerentes que atuavam nas empresas, suas idéias serviam de guia na tentativa de adaptar-se às mudanças organizacionais que modifica- 
vam e desqualificavam as funções da média e baixa gerência, o que pode ser confirmado nas opiniões de alguns empresários. Segundo Celso Calia, então diretor de planejamento da empresa de autopeças Garrett, "a experiência da Semco é o grande acontecimento na área de administração e fonte de inspiração para os que têm necessidade de reformar as relações dentro da empresa". Na mesma direção, Felipe Westin, diretor de recursos humanos da subsidiária brasileira da Monsanto: "a Semco é um exemplo extremamente positivo de inovação na área das relações trabalhistas, sendo que seu fenômeno tem que ser estudado com muito carinho" (revista Exame, Suplemento Maiores e Melhores, agosto de 1990).

Já para os postulantes aos cargos gerenciais, a interpretação de Ricardo Semler sobre o envolvimento operário fornecia uma poderosa arma na luta por posições nas empresas, que se tornava cada vez mais acirrada com a redução dos níveis hierárquicos e a simplificação das estruturas da empresa. Um indicativo de tal fato era a presença constante do nome de Semler na lista de homenageados das escolas de engenharia e administração no período. Ele disputava espaço nas indicações com nomes tradicionais do empresariado brasileiro como Antônio Ermínio de Moraes (grupo Votorantin) e José Mindlin (Grupo Metal Leve), contanto para isso com justificativas que aliavam uma "nova forma de gerenciar as empresas" à imagem de juventude de Semler.

A divulgação alcançada na imprensa levou diversos grupos de empresários e estudantes a visitar a fábrica no bairro de Santo Amaro, em São Paulo. Entre 1988 e 1990, mais de mil pessoas estiveram em suas instalações; entre os participantes figuravam o grupo financeiro Chase Manhattan, a construtora Mendes Júnior e a metalúrgica Continental 2001.

A divulgação alcançada por Semler possibilita visualizar aspectos relevantes da dinâmica do campo formado em torno do tema "participação" no final da década de 80. Entre eles, cabe ressaltar o processo de "entre-legitimação" que ocorreu entre a imprensa de negócios e Semler. Para a primeira, que no decorrer da década valeu-se da divulgação de notícias sobre mudanças organizacio- nais como o principal instrumento de sua consolidação no meio jornalístico, o sucesso das propostas de Semler conferia legitimidade e realimentava as possibilidades de atuação. Em contraponto, a "participação" associada a uma ferramenta gerencial, com o objetivo de tornar o grupo de trabalhadores capaz de resolver problemas cotidianos da produção, visando o aumento de flexibilidade, produtividade e tornando desnecessária a supervisão direta, como postulado por Semler, encontrava na imprensa de negócios uma importante fonte de divulgação. Este fato veio incrementar o processo de isomorfismo mimético e também fortalecer as posições dos agentes do campo que atribuíam um conteúdo gerencial ao tema.

\section{A visão sindical de "participação" no final dos anos 80}

Da mesma forma que na imprensa de negócios e nas empresas, no universo sindical o conceito de "participação" também passava por transformações no final da década de 80. Os artigos do Boletim do Dieese começavam a fazer referências à introdução de "trabalho participativo" nas empresas. Entretanto, não havia uma diferença clara de significados entre o "trabalho participativo" e os CCQs. Os dois mecanismos eram entendidos como formas de apropriação, por parte das gerências, de conhecimentos dos trabalhadores quanto ao funcionamento da fábrica e que se contrapunham à versão sindical de "participação", associada às Comissões de Fábrica.

Mas ao se comparar os artigos que tratam da introdução dos CCQs, no período de 1982 a 1987, com aqueles que fazem referências ao "trabalho participativo" no final da década, nota-se diferenças significativas. No primeiro caso, os CCQs eram apresentados como uma forma de "participação da gerência”, e as Comissões de Fábrica eram tratadas como o contraponto sindical da "ferramenta" gerencial. Já nos artigos sobre o "trabalho participativo", as Comissões de Fábrica assumem um papel de opositor direto mitigado. Em alguns casos, elas eram consideradas fontes de informações para que o sindicato pudesse negociar os proces- 
sos de mudanças organizacionais; uma espécie de "ferramenta sindical" e, portanto, instrumento despido de suas características libertárias de momentos anteriores. A pesquisa do Dieese, "Trabalhadores e inovações tecnológicas, demandas e perspectivas" de 1989, seguia a mesma direção dos artigos do Boletim, ou seja, a "participação" estava relacionada à obtenção de informações sobre a introdução e a implementação das mudanças organizacionais.

Assim, pode-se verificar a diminuição na importância do papel das Comissões de Fábrica na construção do conteúdo associado ao conceito de "participação". No início da década, elas tinham um papel fundamental, contando para isso com a divulgação alcançada pelas questões trabalhistas após 1978. Na metade da década, a disputa pelo significado atribuído ao tema encontra-se em uma situação de equilíbrio, tendo duas referências principais: as Comissões e os Círculos de Controle de Qualidade. Já no final da década, propagamse as idéias que associavam à "participação" características de uma ferramenta e atributo gerencial, com as comissões assumindo um papel secundário na formulação do conceito.

Pode-se tecer duas hipóteses sobre o desfecho do processo no que tange o papel dos sindicatos. De um lado, supõe-se que, com a consolidação das centrais sindicais, a principal atenção dos militantes da área tenha sido canalizada para questões macro-estruturais ou institucionais, por exemplo, a atuação da Central Única dos Trabalhadores no Programa Brasileiro de Qualidade e Produtividade e nos fóruns institucionais de debates sobre as "novas tecnologias" e no processo de elaboração da Constituição de 1988.

Outra hipótese, não necessariamente antagônica, é a simples incapacidade de o movimento sindical manipular em seu proveito as novas tecnologias organizacionais. É possível constatar um indício de tal fato em uma entrevista que nos foi concedida pelo diretor de Base dos Metalúrgicos do ABC paulista, uma das pessoas que vivenciou o processo de implantação e desenvolvimento das Comissões de Fábrica na Volkswagem. O entrevistado reafirmava a posição de associar as comissões ao conceito de "participação". Lembrava das primeiras tentativas da Volkswagen de "trazer os trabalhadores para a empresa" com os Programas de Sugestão, mas apontava os CCQs como o principal mecanismo que as empresas utilizaram para combater as Comissões de Fábrica. Entretanto, ele admitia a introdução da "Administração Participativa" e de outras formas mais recentes de "participação como ferramenta gerencial", mas não conseguia pesar as conseqüências dessas novidades para o trabalho de mobilização operária, a exemplo do que se passou na contraposição anterior entre os CCQs e as Comissões de Fábrica.

\section{Síntese do período}

Assim, concluindo a cronologia do período, pode-se dizer que o conceito de "participação" percorreu um caminho peculiar na sociedade industrial brasileira dos últimos vinte anos. Ele começou sua "carreira" como ponto fundamental das estratégias mais radicais do movimento operário, que se confrontava com o peleguismo sindical e o autoritarismo governamental, para chegar ao limiar do século XXI como uma ferramenta gerencial quase perfeitamente pasteurizada. No final da década de 70, o campo estruturado em torno da "participação" ainda não apresentava um pólo dominante claramente desenvolvido. Naquele momento, membros do movimento sindical disputavam espaço (principalmente o espaço simbólico) com os gerentes que começavam a se apropriar do conceito. No decorrer dos anos 80, a balança do poder pendia cada vez mais para o lado gerencial. No final da década, mal podia ser percebido o papel dos sindicatos no tratamento do tema, indicando que no período ocorreu um fenômeno praticamente completo de apropriação dessa temática pelo universo gerencial.

Além disso, ilustrando o fenômeno que Bourdieu chama de "alongamento dos circuitos de legitimação", ${ }^{6}$ os diversos grupos, na condição ao mesmo tempo de homens de ação e de intelectuais do novo tempo, aparecem para o público engajados principalmente em uma forte concorrência pela primazia da palavra final sobre o significado de "participação" e de outros termos que 
entraram no cotidiano econômico. Mas não podemos nos deixar enganar pelas aparências: talvez o principal resultado social dessa disputa seja o fato de ela se produzir em um processo de "entre-legitimação", no qual uns se apóiam nos outros através da recuperação parcial das construções de sentido já produzidas pelos seus contendores, procurando flexioná-las para nuanças que lhes seriam mais convenientes.

Nua e cruamente, todos os atores "estão no mesmo barco". O conceito divide a representação do patronato paulista exatamente no momento conturbado em que a velha elite da Fiesp defronta-se com os "jovens turcos" no final da década de 70 (permanece em aberto a questão de saber em que medida essa ruptura no seio do patronato abre espaço para que o conceito de "participação" adquira legitimidade em meios possivelmente subordinados funcional e ideologicamente, como o dos gerentes). Entre os gerentes, as diversas gerações, funções e origens disciplinares e sociais evidenciam suas diferenças por meio da apreciação de "se-e-como se deve permitir ou patrocinar a participação". Na academia, candidatos a diversos tipos de notoriedade digladiam-se, cada qual "conceituando" o tema de acordo com algum princípio que mistura aparência de rigor científico com uma plataforma para propaganda de consultoria, tentando mesclar justamente autoridade científica com dinamismo intervencionista. Mesmo entre as lideranças operárias, tensionadas pela questão do monopólio da representação de suas bases, aparecem conflitos táticos e semânticos envolvendo o tema da "participação".7 A aparente independência e mesmo antagonismo entre os diversos grupos faz com que o conceito juntamente com os agentes que o verbalizam ganhem todos muita legitimidade, segundo o princípio de que a máxima legitimidade é alcançada quando o consagrador esteja simbolicamente o mais distante possível do consagrado. Mais ainda, como o conceito é construído e reconstruído incessantemente pelo trabalho cognitivo dessa afinidade de agentes e grupos, torna-se uma "obra sem autor", com caráter auto-evidente ou, pelo menos, sua veracidade é fortalecida. Ao participar da luta simbólica pela elaboração do conceito de "participação", a elite sindical insere-se no campo do poder - locus onde os possuidores das diversas formas de capital existentes na sociedade interagem, cada qual querendo fazer registrar como mais legítima a forma de que é detentor. E, dessa maneira, acompanhando análises mais recentes relativas à construção da semântica dos novos tempos, observamos um caso bastante representativo do processo pelo qual o capitalismo se reforma e se fortalece apropriando-se da sua crítica (Boltanski e Chiapello, 1999) - e talvez também de seus críticos.

\section{NOTAS}

1 Três tipos de inspiração teórica nos animam: o primeiro está contido na generalidade dos trabalhos de Bourdieu e sua escola, podendo ser rapidamente acessado em P. Bourdieu e L. Wacquant (1996) e L. Pinto (1999); a segunda vertente, mais diretamente pautada no estruturalismo, está bem explicada em R. d'Andrade (1995); e a terceira, exterior ao quadro geralmente aceito das Ciências Sociais, em A. Ortony (1993). Um dos proponentes tentou enveredar por esse caminho em reunião anterior da Anpocs evidentemente a partir de um instrumental analítico menos desenvolvido: Ver M. Zilbovicius, J. R. Ferro e R. Grün (1986).

2 Com as mudanças nas relações trabalhistas e o fortalecimento dos movimentos sindicais, as empresas começavam a se reciclar para as negociações diretas com seus empregados. Luiz Carlos de Queiros Cabreira, diretor da PMC\&A, firma de seleção de executivos, enunciava uma das principais tendências do campo executivo da época: "Houve um aumento da procura de profissionais de recursos humanos, de preferência executivos mais experientes e com conhecimentos em relações trabalhistas" (Donadone, 1996). A necessidade de estabelecer um diálogo mais permanente e formal com os empregados a respeito das condições de trabalho passava a ser admitida por grande parte das empresas brasileiras. Entre as diversas formas de aumentar a identificação dos funcionários com a empresa surge com constância e evidência a criação de "representantes dos trabalhadores". Os representantes tinham a função de estabelecer um canal de comunicação entre os operários e os empregadores, na tentativa de diminuir os problemas trabalhistas e amenizar a influência do sindicato sobre os trabalhadores.

3 É um ponto a ser explorado a relação entre a sensibilidade da imprensa de negócios para o tema e o 
fato de nela estarem presentes em posição de destaque jornalistas simpáticos a causas da esquerda, como Bernardo Kucinski e Rui Falcão.

4 Como desenvolvido em Donadone (2000), o entendimento de como ocorre a construção e a legitimação do guru gerencial brasileiro encontra-se intrinsecamente relacionado ao histórico da formação e consolidação da imprensa de negócios brasileira, sua influência na divulgação de "novidades gerenciais" e nos mecanismos que constroem e legitimam a utilização de "formulações propostas pelos gurus" nos meios empresariais e gerenciais.

5 Ver R. Manoff e M. Schudson (eds.) (1987).

6 P. Bourdieu (1989, p. 548).

7 Ver M. Zilbovicius, J. R. Ferro e R. Grün (1986).

\section{BIBLIOGRAFIA}

ANDRADE, R. de (1995), The development of cognitive anthropology. Cambridge, Cambridge University Press.

BOLTANSKI, L. e CHIAPELLO, E. (1999), Le nouvel esprit du capitalisme. Paris, Ed. Gallimard.

BOURDIEU, P. (1989), La noblesse d'état. Paris, Ed. De Minuit.

BOURDIEU, P. e WACQUANT, L. (1996), Réponses. Paris, Ed. du Seuil.

COLE, R. (1989), Strategies for learning: small group activities in American, Japanese and Swedish industry. Berkeley, University of California Press.

DIEESE (1994), Trabalho e reestruturação produtiva: 10 anos de linha de produção. São Paulo.

DONADONE, J. C. (1996), Reestruturação produtiva e mudanças organizacionais: a difusão dos sistemas participativos na década de 1980. Dissertação de mestrado. São Carlos, Departamento de Engenharia de Produção, Universidade Federal de São Carlos, março.

(2000), Imprensa de negócios, dinâmica social e os gurus gerenciais. I En- contro de Estudos organizacionais/ENEO. Associação Nacional de Pesquisa em Administração/ANPAD. Curitiba, junho.

HUCZYNSKI, A. (1993), Management gurus. What makes them and how to become one. Nova York, Ed. Routledge, Chapman and Hall, Inc.

IACOCCA, L. (1986), An Autobiography. New York, Bantam Books.

MANOFF R. e SCHUDSON, M. (eds.) (1987), Reading the news. Nova York, Pantheon.

ORTONY, A. (ed.) (1993), Metaphor and thought. Cambridge, Cambridge University Press.

PINTO, L. (1999), Pierre Bourdieu et la théorie du monde social. Paris, Albin Michael.

POWELL, W. W. e DI MAGGIO, P. J. (1991), "The iron cage revisited: institutional isomorphism and collective rationality in organizational fields", in The new institutionalism in organizational analysis. Chicago, University of Chicago Press.

REVISTA Exame. (1967-1990). São Paulo, abril, 1648.

SEMLER, R. F. (1988), Virando a própria mesa. São Paulo, Best Seller.

ZILBOVICIUS, M., FERRO J. R. e GRÜN R. (1986), Novas estratégias patronais e novas respostas operárias: a operação Vaca Brava. $10^{\circ}$ Encontro Nacional da Anpocs, Campos de Jordão.

YOKOYAMA. N. (1997), O TQC em Exame. Dissertação de mestrado. São Carlos, Departamento de Engenharia de Produção, Universidade Federal de São Carlos, março. 
PARTICIPAR É PRECISO!: MAS DE QUE MANEIRA?

\author{
Júlio César Donadone e \\ Roberto Grün
}

Palavras-chave

Participação; Sindicalismo; Polissemia; Qualidade; Conflito cultural.

Este artigo investiga as flexões semânticas do significado hegemonicamente atribuído ao termo "participação" no contexto organizacional e trabalhista do Brasil dos últimos trinta anos, a partir de suas expressões na imprensa, particularmente a de negócios e a voltada para temas trabalhistas, e também, com menor grau de cobertura, em boletins sindicais e material de consultoria empresarial. O texto procura evidenciar a existência de um intenso processo de luta simbólica pela definição do conceito que reflete, ainda que de maneira não biunívoca, as diversas fases e vicissitudes por que passou o movimento operário e os embates internos ao espaço empresarial brasileiro no período, constituindo-se em uma excelente porta de entrada para uma análise do chamado "campo do poder" na sociedade brasileira. Este artigo historia o processo, tentando periodizar as fases da luta simbólica e extrair um mapa das mudanças de sentido observadas em relação ao conceito de "participação", insistindo sempre na dinâmica social que explica as transformações e a polissemia.

\section{PARTICIPATION IS NEEDED! BUT HOW?}

\author{
Júlio César Donadone e \\ Roberto Grün
}

\section{Keywords}

Participation; Trade Unionism; Polysemy; Quality; Cultural Conflict.

The article seeks to investigate the semantic inflections of the hegemonically attributed meaning of the term "participation" in the Brazilian organizational and labor context over the last three decades, based on its expressions in the press, particularly that related to business and labor issues, but also, to a lesser extent, on trade union bulletins and on business consulting material. Based on the collected data, the article identifies the existence of an intense symbolic struggle for a definition of the concept, which would reflect, albeit not unequivocally, the different phases and vicissitudes that the workers' movement and the adversities within the Brazilian business community underwent during this period, constituting an excellent start for an analysis of the so-called "field of power" in the Brazilian society. The text seeks inspiration from the cognitive sciences for a sociological analysis as well as a history of the process, attempting to divide the phases of the symbolic struggle into periods and to map the changes that the meaning of the word has undergone, consistently emphasizing the social dynamics that could explain its transformations and polysemy.
PARTICIPER EST NÉCESSAIRE!: MAIS DE QUELLE FAÇON?

\author{
Júlio César Donadone et \\ Roberto Grün
}

\section{Mots-clés}

Participation; Syndicalisme; Polysémie; Qualité; Conflit culturel.

Cet article recherche les flexions sémantiques du sens hégémoniquement attribué au terme "participation" dans le contexte organisationnel et du travail au Brésil, au cours de ces 30 dernières années. Cela est fait à partir des expressions de ces flexions dans la presse, particulièrement celle d'affaires et tournée vers des thèmes du travail, et aussi avec une couverture moins importante - dans les bulletins syndicaux et le matériel de conseil aux entreprises. Le texte cherche à mettre en évidence l'existence d'un processus intense de lutte symbolique pour la définition d'un concept qui reflète, encore que de manière non biunivoque, les diverses phases et vicissitudes par lesquelles sont passés le mouvement ouvrier et les luttes internes à l'espace de l'entreprise brésilienne dans cette période, constituant une excellente porte d'entrée pour une analyse de ce qui est appelé le "champs du pouvoir" dans la société brésilienne. Cet article raconte l'histoire d'un processus, en tentant de classer en périodes les phases de la lutte symbolique et d'extraire une carte des changements de sens observés par rapport au concept de "participation", en insistant toujours sur la dynamique sociale qui explique les transformations et la polysémie. 